\title{
Experiences as Complex Events
}

\author{
Michael Jacovides
}

\begin{abstract}
The author argues that experiences are complex events that befall their subjects. Each experience has a single subject and depends on what it is of, either a state or event. An experience depends on its subject, its grounding event or state, and everything that the subject is aware of during that time that's relevant to the telling of the story of how it was to participate in that event or be put in that state. The experience occurs where the person having the experience is. An experience of an event or state occurs when that event or state makes a difference to its possessor's conscious life, where this difference is either a matter of really knowing what's happening or merely a matter of being affected.
\end{abstract}

Biographical sketch:

Michael Jacovides is an associate professor of philosophy at Purdue University. His primary area of specialization is early modern philosophy. His publications include "How is Descartes’ Argument Against Scepticism Better than Putnam’s?,” “Locke’s Resemblance Theses," and "Hume's Vicious Regress."

Suppose, following John Dewey (1929, Ch. 1), Crispin Sartwell (1995), Charles Travis (2004), and William Alston (2005), we concluded that experiences don't represent anything. ${ }^{1}$ What positive account of experience should be built on this foundation?

\footnotetext{
${ }^{1}$ I presented an ancestral version of this material at the 2003 Pacific APA with Bernard Kobes commenting. I'm grateful to Kobes and to various audience members for their questions and comments. I received detailed, useful comments on drafts from Jeff Brower, Simon Evnine, Amy Kind, Alex Rajczi and several anonymous
} 
Some might be interested in this question for the same reason that historians of ideas are interested in drawing out consequences of unlikely doctrines in Plotinus or Leibniz. Others might be more sympathetic to the possibility that experiences don't represent, but want to have certain doubts resolved. For example, they might worry that a nonrepresentational account of experiences can't explain how experiences justify beliefs. For such readers, my project might serve as proof of concept. More optimistically, my account of experiences as non-representational events might be so attractive that it helps justify the doctrine that experiences don't represent. I am myself convinced that experiences (ordinarily so-called) do not represent, ${ }^{2}$ and what follows is my best attempt to give a positive account of what they actually are. In the first part of the paper, I'll say something about the metaphysical structure of experiences. In the second part, I'll say something about where and when they occur.

\section{Participants}

\subsection{Experiences as Events}

Events are often distinguished from ordinary objects by their relation to time. I am entirely present in the room. My life is not. Though every part of me is in this room, most parts of my life are not. Qualities and states seem to inherit the relation to time of the substances in which they inhere. If I am entirely present in a room, then so is my stature and my grumpiness.

Experiences stretch out over time. Your experience of reading this paper, for example, might last about twenty minutes. Experiences are never wholly present to the mind

commentators. I've had useful conversations on the subject with many people, including Fiona Cowie, Janet Levin, and David Owen.

${ }^{2}$ I give my arguments in Jacovides (2010). 
at a time, except insofar as we remember them, not unless the experience is very brief. You only get to read a little bit of this paper at a time, however much you might want to get it all in an instant. Long experiences unfold; they occur over stages. Each experience constitutes, in Ryle’s phrase (103), “a sub-stretch of my life-story.” I conclude, with Charles Siewert (11), Brian O’Shaughnessy (42), and Alex Byrne (\$2.1), that experiences are events. Michael Tye (332) writes, "Token experiences are events (in the broad sense, which includes token states)". I would go so far as to say that they are events in the narrow sense that excludes states. States, unlike experiences, are present all at once.

This way of distinguishing between events and objects is controversial. Sider (1997) challenges the intelligibility of the distinction. Hawthorne's explanations (2008) don't seem to capture its spirit. Fine's attempt (2006) seems better and true, but perhaps doesn't get at the heart of the matter. If it turns out that there's nothing to the distinction between events and enduring objects, my paper might still have some value. I will have given a description of an unusually interesting sort of space-time worm.

That experiences are events is perhaps the first fact about experiences, and everything else that one says about the subject should be compatible with it. I suspect that when philosophers fail to find intrinsic qualities of experiences, the problem often is that they are barking up the wrong categories. In an important paper, Gilbert Harman argues,

When you attend to a pain in your leg or to your experience of the redness of an apple, you are attending to a quality of an occurrence in your leg or a quality of the apple. Perhaps this quality is presented to you as an intrinsic quality in your leg or as an intrinsic quality of the surface of the apple. But it is not at all presented as an intrinsic quality of your experience (41).

True enough, but pain is a sensation and not a quality. The relevant quality here, I would have thought, is being painful. Surely, the experience of having a pain in your leg is intrinsically and essentially painful. The experience is painful because the pain is painful, and 
the pain is part of the experience. It's obvious to the sufferer that the experience is painful, so the experience is presented as painful.

Red is a quality, but not a quality that most events can have. Explosions and flashes may be exceptions, but they are unusual events that seem to lack substrata. The fact that experiences can't be red just goes to show that experiences are ordinary events in this regard. A party can't be red, not even a party at a firehouse where all the guests wear red pants. In order to investigate the intrinsic qualities of experiences, we ought to examine qualities that ordinary events can bear. Parties can last until three in the morning. Parties can be drunken, exciting, or enjoyable. Can experiences last until three in the morning? Can they be drunken, exciting, or enjoyable? Yes, of course.

Almost all events depend on at least one enduring object. Explosions and flashes again might be counter-examples, but I'll set them aside. Most events are complex in that they depend on more than one enduring object. ${ }^{3}$ These involved objects are agents from which the event arises, patients which the events befall, or neither agents nor patients, but nevertheless participants in the event. The officiant is an agent in a wedding. The bride and groom are both agents and patients. The surroundings and the guests participate in one way or another.

Peter Simons asserts, "no occurrent is part of a continuant and no continuant is ever part of an occurrent" (306). I don't think that we have any sufficient reason to believe this. Perhaps Simons is worried about fending off the fallacious inference from $A$ is part of $B$ and $B$ is an occurrent to $A$ is an occurrent, as if playing in a hockey game would make you divisible

${ }^{3}$ This is a different definition of 'complex event' than that offered by Philip Peterson (1989), according to whom complex events are those that contain other events as constituents. Though I don't want to commit myself to all the details of Peterson's analysis, on my account, almost all experiences will be complex in his sense as well as in mine. What I'm calling complex events are akin to what Jaegwon Kim called "dyadic and higher-place events" (161), though I wouldn't want to commit myself to the details of Kim's account. 
into three periods. This may just be a linguistic dispute, since 'part' is said in many ways. At the very least, hockey players take part in hockey games. Simons refers to the participation relation that I have in mind with the vague word 'involving' (130n3, cf. Lombard 120-27). I'll use 'participant' for the relation that holds between ordinary objects and the events they are involved in and 'constituent' as a generic term for participation, parthood, membership and the like.

In this paper, I'll describe the conditions of unity and participation for experiences. As a consequence of this account, it will turn out that almost all experiences are complex events. The spirit behind my project is the same one that guided Barry Smith's analysis of perceptions as 'relational acts' that are “formally indistinguishable from relational actions and events such as promisings, fights, thefts, conversations, kissings, hittings, weddings, greetings, and so forth" (173). I won't appeal to any particular analysis of perception or introspection, however. Instead, I'll treat $x$ is aware of $y$ as a primitive relation that human beings can stand in with respect to external and internal objects and offer an account of experiences that depends on that relation.

\subsection{Subjects of Experiences}

The primary participant in every experience is always the person who has it. Experiences depend on awareness, and awareness requires a conscious living subject who is aware. Thus, on any reasonable account, an experience will happen to at least one subject.

Strictly speaking, an experience will happen to at most one subject. We do talk about shared experiences, and I take such locutions seriously. In the end, however, I think that shared experiences are, at most, higher order complex events that overlap the more basic personal experiences. If Jack and Jill walk up a hill they share an experience. Even so, Jack's 
experience might be pleasant while Jill's is unpleasant. I infer that Jack's experience is, at some level, a distinct experience from Jill's.

A referee objects to the lesson I draw from Jack and Jill: "here's an alternative construal: their experience might be pleasant to Jack but unpleasant to Jill. This is consistent with its being one experience." I'm not inclined to go that way. It seems to me that being pleasant is an intrinsic feature of experiences, at least at the root level. Since being intrinsically pleasant is incompatible with being intrinsically painful for basic experiences, Jack and Jill can't be having the very same basic experiences, though we might try to construct collective experiences out of their individual ones.

There are degrees of commonality in experience and the proper analysis of these degrees might require appeal to particular facts about particular objects, events, or occasions. If Jack and Jill walk up a hill at the same time, they share an experience in a stronger sense than if they walk up the hill on different days or if they walk up different hills. Even in the cleanest and best examples of shared experiences, however, there will always be a difference in perspective and affect, and, thus each basic experience will happen to at most one subject.

\subsection{Grounding Events and Grounding States}

We should be careful to distinguish between experiences and what they are of. J. J. C. Smart (150-51) rightly contrasts after-images with the experience of having an after-image. I don't agree with his further, substantive claims (experiences are brain processes and after-images are nothing at all) but the distinction ought to be drawn.

In my treatment, the canonical description of an experience will be "so-and-so's experience of $\phi$ " where $\phi$ is replaced by an expression for an event or a state and where soand-so is the subject of the experience. Descriptions where $\phi$ is replaced with an expression 
for an ordinary object are, I think, elliptical for descriptions in my canonical form.

Depending on context, 'Hannah's experience of a hot tub' might mean Hannah's experience of owning a hot tub, or Hannab's experience of soaking in a hot tub, or Hannab's experience of sensing a hot tub. If I am mistaken and there are experiences of objects that aren't really experiences of events or states, then my account won't apply to them. ${ }^{4}$

I'll describe the referent of an appropriate substitution for $\phi$ as a 'grounding event' or a 'grounding state.' The grounding event or state can be psychological as in Ken's experience of having a flashback or Jake's experience of having nausea. The grounding event or state can be half psychological and half objective, as in Tom's experience of being surprised by a bat or Frank's experience of looking at a red tomato. The grounding event or state can also be almost entirely outside the mind, as in Norgay's experience of climbing Mt. Everest or Pierre's experience of being the prime minister of Canada.

No matter how things seem, the grounding event or state of an experience must actually happen to the person undergoing an experience. To have the experience of swimming across the Euphrates, it isn't enough to think that you've swum the river. If someone swims across the Tigris, but thinks that she's swum across the Euphrates, she's had the experience of swimming across the Tigris and not the experience of swimming the Euphrates. She may have had an experience as of the experience of swimming the Euphrates, but that's just to say that she's had an experience that's like the experience of swimming the Euphrates. Having the experience itself depends on the grounding event of actually swimming the river (cf. Sartwell 58).

Experiences depend on their grounding events or states. Grounding events depend on their essential participants. Since dependence is transitive, it follows that an experience of

\footnotetext{
${ }^{4}$ I'll say a little more about my somewhat ecumenical attitude to alternative conceptions of experience in $\$ 1.5$.
} 
an event cannot occur without the essential participants in its that event. Nor can an experience of a state occur without any subject in which the state inheres and depends. You can have neither the experience of being on a boat on the Euphrates nor the experience of swimming across the Euphrates without the Euphrates river.

The most straightforward way to make sense of this dependence is to say that grounding events and states are essential constituents of experiences. Generally speaking, representations can represent things that don't exist. For example, there are statues of Zeus. If experiences represented their grounding events, we would expect some of them to represent non-occurring grounding events.

The experience of being in a car wreck might leave its subject bruised and frightened. The experience of sliding down a hill in a sled might leave its subject giddy and cold. The experience of chasing a sparrow out of the house might leave its subject sweaty and pleased. I think that the following sentence expresses a truth: "Alumni who played football in universities tend not to donate money, because they've usually been injured by their experiences on the field." On the view that experiences are strictly mental states, this sentence would turn out to be nonsense. On any view, one might emphasize that it is more than anything the violent contact with other players that causes injuries. Still, I think, 'experiences' is the mot juste in the example. We want to refer to both the physical processes that narrowly cause the injuries and also to the subjective reactions that explain why the alumni do not donate. If we treat playing in a football game as a constituent of the experience of playing in a football game, then we can capture the physical side of that intuition. 


\subsection{Extraneous Participants}

A full account of experiences will provide us with a full account of the all the participants in the experience and explain how those participants relate to the subject of the experience. We aren't done yet, since experiences have participants beyond their subjects and beyond their grounding events and states.

Playing in the championship match at Wimbledon is, I imagine, exhilarating. Likewise, the experience of playing in the championship match at Wimbledon is exhilarating. The experience, however, seems to include elements that the match does not. The experience of playing the match may include noticing one's mother in the stands, but playing a tennis match doesn't include noticing one's mother. The players in a game are the participants in the game, while the spectators are on the outside looking in. That's the difference between players and spectators. The mother doesn't participate in the player's match, even though she's part of his experience of the match.

According to J.M. Hinton, the ordinary experience of $X$-ing "is no other event or or thing than $X$-ing, the event of which one is the grammatical subject" (6). If some experiences include elements that don't participate in the grounding events of those experiences, then Hinton is mistaken. Experiences shouldn't be identified with the events that ground them, since they can include more constituents than those grounding events.

Under what conditions do elements beyond subjects and grounding events participate in the subject's experience? According to G.E. Moore, "that peculiar relation which I have called 'awareness of anything' ... is involved equally in the analysis of every experience" (452). I'll use this insight to construct an approximation of participation in an experience and then refine the approximation in light of counter-examples. 
My approximation is that an experience includes not only the grounding event or state but also everything that the subject of the experience is aware of while the grounding event or state takes place. If Smith is aware of the buzzing of a fly while she takes an exam, then her experience of taking the exam includes the buzzing of the fly. This is so even though the buzzing of the fly is no part of her taking the exam. On this account, experiences are richer in some respects than their grounding events or states. Anything that one can be conscious of can be included in an experience, including rattles, buzzings, smells, moods, pains, tingles, the visual field, decisions, changes of heart, and revelations.

The present account, however, seems to let too much in. Suppose that I've been in an accident and injured both my ankles at the same time and that they heal at the same rate. One might think that defenders of this account are committed to saying that the experience of having a pain in my left ankle is identical to the experience of having a pain in my right ankle. ${ }^{5}$ It's not obvious that they are thus committed. Two things can have all the same constituents and be distinct, for example, the set $\{3,4,5\}$ and the sequence $<3,4,5>$. Still, the account under consideration has unacceptable consequences. I am perfectly happy to say that applying ice to my left ankle is part of my experience of having a pain in my left ankle. I am not happy to say that applying ice to my right ankle is part of my experience of having a pain in my left ankle.

Even if someone were willing to bite the bullet on this example, the account comes to grief with long experiences that aren't central to one's life. Consider the experience of being allergic to cats. Surely, if someone asks another person about this experience, she doesn't want to hear the complete life story of everything that the allergic person has been

\footnotetext{
5 This is Amy Kind's example, and it refuted a previous version of the paper. Another questioner, whose name I don't know, raised a similar point at my APA session; it took me a little while before I saw its justice.
} 
aware of since discovering his allergy. Some sort of relevance condition needs to be imposed.

The problem with the approximate account is connected to a point that Dewey made: some things that we are aware of don't hang together as a single experience. "Oftentimes," he writes, "things are experienced, but not in such a way that they are composed into an experience" (1958 35). ${ }^{6}$ For Dewey, we can be aware of things that aren't united into a single experience. He first describes "inchoate" experience:

there is distraction and dispersion; what we observe and what we think, what we desire and what we get, are at odds with each other. We put up our hands to the plow and turn back; we start and then we stop, not because the experience has reached the end for the sake of which it was initiated but because of extraneous interruptions or of inner lethargy (ibid.).

He contrasts this undifferentiated mass of experience with particular, unified experiences:

In contrast with such experience, we have an experience when the material experienced runs its course to fulfillment. Then and then only is it integrated within and demarcated in the general stream of experience from other experiences. A piece of work is finished in a way that is satisfactory; a problem receives its solution; a game is played through; a situation, whether that of eating a meal, playing a game of chess, carrying on a conversation, writing a book, or taking part in a political campaign, is so rounded out that its close is a consummation and not a cessation. Such an experience is a whole and carries with it its own individualizing quality and self-sufficiency. It is an experience (ibid.).

His conclusion is that only events that come to a satisfactory conclusion make up an experience.

It seems to me that Dewey's examples do not support his conclusion. Experiences can be incomplete, unsatisfying, and crummy. The experience of making a shoddy

\footnotetext{
${ }^{6}$ Dewey's italicization of the indefinite article points to an important distinction, between experiences as the referents of a count noun and experience as the referent of a mass noun. Throughout this paper, my concern has been with individual, countable experiences.
} 
birdhouse, of struggling fruitlessly with a problem, and of playing an interrupted game of chess are all genuine individual experiences.

I don't want to make too much of this. Dewey is pretty clearly talking about a particular and idiosyncratic notion of experience. On the next page, he uses the expression "experience in this vital sense", and I do not want to fight over words. Moreover, he is plainly on to something. Consider everything that you were conscious of between 10:20 a.m. and 11:45 a.m. yesterday. Clearly, those states and events do not constitute a single experience, especially when compared to some of Dewey's examples. As examples of experiences with the requisite unity, he lists "that meal, that storm, that rupture of friendship" (1958 37).

The examples of the storm and the ruptured friendship show that, even by Dewey's own lights, the satisfactoriness and success of the grounding event or state aren't necessary conditions for the objects of awareness to coalesce into an experience. He is on firmer ground when he suggests that narrative unity is a precondition for particular experiences. Ordinary speech, he tells us, picks out particular experiences, because life "is a thing of histories, each with its own plot, its own inception and movement toward its close, each having its own particular rhythmic movement" (1958 35-36). What you did between 10:20 and 11:45 doesn't compose an experience, because it does not have the requisite narrative unity.

Saying this doesn't add much to my previous remark that we need to institute a relevance condition, but it adds a little. If we ask someone to recount some experience of his, we want him to tell us the story of how some event or state was for him. That means that we want him not only to describe his first hand acquaintance with what the experience is of, but also his subjective reactions, and everything else that fits into a proper and full 
telling of the tale. What's relevant is not exactly whether the details help describe how the grounding event unfolds, but rather whether the details help describe how it was for the person who underwent it.

Here, one might think, my account comes into contact with the main current of analytic philosophy of mind. Qualia, we are sometimes told, are what it's like to have an experience. I say that the elements of an experience are those things that are relevant to telling the story of what it is like to undergo the grounding event or state. Are these qualia?

I don't know. Here's an example of what I mean by a description of what it's like to undergo a grounding event: "The parking was a hassle and we got really hot and thirsty waiting in the sun, but then the music started, and the crowd got into it, and it was a lot of fun." If that counts as a description of qualia, then I'm talking about qualia. If not, then I'm not.

I conclude that there are three paths to participation in an experience: first, a person (or animal) can participate in an experience by having the experience; second, something can participate in an experience by being a substratum of a grounding event or state; and, third, an enduring thing can be an object of awareness (or the substratum of an object of awareness) and relevant to telling the story of what it was like for the subject to undergo the grounding event or state. These are the participants in an experience.

\subsection{Inner Objects and Illusory Objects}

From this account of the constituents of experiences, it follows that our experience of having a mental state ought not be identified with the mental state itself. Suppose that I'm delivering a talk and I have a stabbing pain in the belly. The pain is so great that I collapse to the floor, and members of the audience gather around to see if anything can be done. An 
ambulance is summoned, and I am brought to the hospital. My falling to the ground, the concerned faces of the on-lookers, and the trip to the hospital are all parts of my experience of having a stabbing pain in the belly, assuming that I don't pass out. Falling to the ground and being taken to the hospital are not, of course, constituents of the pain itself.

It also follows from my account that most experiences are complex events, since most experiences will involve awareness of external objects. There may be exceptional experiences that aren't complex events. At least in principle, some experiences might not involve the awareness of external objects. Certain meditative experiences or the experience of being placed in a sensory deprivation chamber may be actual examples.

What should we say about the related case of hallucinations? Suppose that Rex hallucinates that there are flowers growing out of the kitchen table. Either the hallucinated flowers have some degree of being or they do not. If they do not, then they aren't constituents of anything, including the Rex's experience of taking mescaline. If they do, then they count as constituents. Let me add that I find Ben Caplan's (2004) argument that we should treat fictional objects and hallucinated objects in the same way convincing. ${ }^{7}$ Those who are likewise convinced and also find Peter van Inwagen's (1977) theory of fictional objects appealing should say something like the following: a hallucinator rightly ascribes various properties to hallucinated objects within his experience, even though the hallucinated object is an impoverished and denuded entity outside of that experience. ${ }^{8}$

What of elation, depression, and other feelings that don't have intentional objects? Do they include external objects? Again, I want to distinguish the feeling of depression and

\footnotetext{
${ }^{7}$ See also Thomasson (1999 88-89).

${ }^{8}$ Amie Thomasson (1999) develops an account like van Inwagen's but better. The general approach is defended by Benjamin Schneider and Tatjana von Solodkoff (2009) against recent objections. Mark Johnston (2004) offers an interesting, realist account of the objects of hallucination.
} 
the experience of feeling depressed on a rainy afternoon. The feeling is a constituent of the experience, but the experience of having the feeling also includes all the other elements that are relevant to telling the story of what it was like to feel depressed at that time and place.

Suppose someone else doesn't want to distinguish elation from the experience of feeling elated at some time and some place. Suppose that a philosopher wants to use 'experience' as a grab bag term that includes feelings, perceptions, and sensations in its extension. So long as my interlocutor is willing to grant that I'm saying interesting things about an ordinary psychological kind, I don't have any substantive complaints if she uses 'experience' in the stipulated sense. To be honest, however, I don't really think that feeling, sensations, and perceptions make for a true natural kind, and I worry that terminology that lumps them together will encourage misleading generalizations from one to the others.

Just as experiences of internal states can include external events, so can experiences of external events include internal states. As I mentioned earlier, Sartwell (69n1) denies that experiences represent. I agree with the spirit of Sartwell's account, but not with some of its details. In particular, it seems to me that he goes too far in sealing off the inner aspects of experience from epistemic access. Sartwell denies, whereas I affirm, that "some aspects of the inner component of experience are epistemically available to the experiencer" (59). There is no reason why we cannot introspect during an experience and, I say, what we find inside our minds may well become elements of our experiences. If I have a headache while attending a funeral, my experience of attending the funeral includes the headache, and the headache is something that I can know about.

If what I've said so far is right, then we can see how experiences can both cause and justify beliefs. They cause beliefs because they are events that befall us. They justify beliefs 
because, by construction, they are composed of elements of which we are aware (cf. Alston 276).

It may be objected that if awareness plays a constitutive role in constructing experience, then it will be impossible for experience to ever lead us astray. Charles Travis provides an excellent account of what he rightly calls the "central" form in which experiences mislead. In such cases, what is actually presented to us in experience gives us good reason to believe something else, yet it turns out that the derived belief is false. He writes,

seeing Luc and Pia's flat strewn with broken crockery, one might reasonably suppose there to have been a tiff. For all that, there may not have been one. Too much champagne at brunch may have led to an excess of exuberance ... . Something we perceive, or experience, may indicate what is not so. What it indicates is what there is reason to think, even when it is not, in fact, so. That is one way perceptual experience may be misleading, other than by representing something that isn't so (66).

So much, I think, is both indisputable and consonant with my constitutive account.

As Travis suggests, there are other ways of being misled by experience. We may be misled by the experience of reading a libelous newspaper, by the experience of suffering from Alzheimer's, by the experience of being surreptitiously placed in Robert Nozick's (4245) Experience Machine, or by the experience of being in the grip of a very powerful demon. The grounding event or state partially constitutes the corresponding experience whether we are aware of this ground or not. If participating in an event or falling into a state misleads us, then we'll be misled by the experience grounded by that event or state.'

\footnotetext{
9 Against Travis, Byrne argues that we can also go wrong when something looks a way that it isn't, where the relevant sense of 'looks' is phenomenal and not epistemic or comparative and cannot be reduced to claims about the 'objective look' of the perceived object (Byrne \$\$4.2-5). Byrne is right about this, I think. There's more to how a thing looks to a person than how that person judges it to be and how the thing objectively looks. Suppose that Audra is on stage in a theater in the round. She looks short to Joan who sees her against the background of taller actors and tall to Sam who sees her against the background of shorter ones. Each knows her objective height which is, let us suppose, perfectly average. Audra, that very woman, is a participant
} 


\section{Places and Times}

\subsection{Locations of Experiences}

So much for the constituents of experiences. Let me turn to the places at which experiences occur. I do this partly because it's interesting in its own right but mostly to fend off an obvious objection. There's surely some sense in which experiences occur where the subject is. How is this fact compatible with my thesis that experiences have extra-mental constituents?

Along the same lines, J. J. Valberg worries (140), "How could the man 'out there', at a distance from my head, be present in my experience, if my experience is something which is occurring 'back up here', inside my head?” Being present, Valberg has argued (130-33), requires more than merely being represented. Thus, he concludes, "Sooner or later it must come home to us that what we mean here by 'my experience' is not something it makes sense to think of as occurring in my head. Or in my soul. Or anywhere else" (140). O’Shaughnessy $(16-17,66)$ also seems inclined to say that experiences have no spatial location. Siewert (341n1) leaves "it open whether experience is in every case, in some sense, an internal event, and whether we are to say it occurs 'in the mind' (or 'subject,' or 'soul,' or 'self'), as opposed to taking place 'outside,' 'in the world."'

Though participation in an experience isn't limited to what's in the head, when we ask where an experience occurred, we are asking where the person who underwent the experience was. For example, if Jones gazes at the stars while taking a walk, then the answer to the question 'where did his experience of gazing at the stars occur?' is given by the path 
he took during his walk and not by the locations of the stars. P. M. S. Hacker offers the following account of this fact:

Psychological events are essentially changes which persons (or other sentient creatures) undergo, not parts of persons ... There is nothing imprecise about saying that A's experiencing so-and-so occurred when A was at such and such a place. We could not have reasons for more precise identifications, for we can give no sense to being more precise in this respect (13-14).

I want to say that experiences are richer than mere changes in subjects and that they may include external substances as participants. Is this a fatal difficulty for my account?

Locating events has been a vexed problem in metaphysics. Since experiences are events, we should expect the difficulties to translate. Aristotle's view was that activities occur in the thing acted upon: "nor is it strange that the activity of one thing should be in another. For the teaching activity belongs to the teacher, still it is in someone else-it is not cut off, but is of one thing in another" (Physics 3.3 202b5-8). ${ }^{10}$ Lawrence Lombard, on the other hand, places events in the agent: "the spatial location of an event is just the location (at the time of the event in question) of all the objects that are minimally involved .... In the case of a's killing of $b$, the only minimally involved object is a; neither b, nor the gun, nor the bullet are involved" (144-45).

In my opinion, the way to resolve such disputes is to heed what Zeno Vendler called "the indirect relation that events have to space" (144). People who ask after the location of an event are looking for answers to one of two questions. Sometimes we want to know where the agent is and sometimes where the patient is. An example from Anscombe illustrates this nicely: “'in New York, A was informing B that p' isn't equivalent to 'in New

\footnotetext{
10 I've used the old-fashioned translation of 'activity' for energeian. Daniel Graham (1980) has shown that is sometimes misleading. For Aristotle, walking is a paradigmatic example of kinesis and not an example of energia. Graham's preferred translation is 'actualization,' but in this context that translation obscures that fact that Aristotle has in mind a species of praxis or action.
} 
York, B was being informed by A that p.” (215). The first sentence tells us where the agent is, and the second sentence tells us where the patient is. Neither fact is profounder than the other or gives us a better fix on the true location of the conversation. ${ }^{11}$

Suppose that Susie strikes Johnny with a snowball. Agent, instrument, and patient are all essential constituents of assault. The question 'where did Susie throw the snowball?' is ambiguous between whither and whence, that is, between where Johnny was and where Susie was. The question "where was Johnny struck by the snowball which Susie threw?" is not ambiguous in the same way. It asks either where Johnny stood or where on his body he was struck. Susie's location isn't relevant, even though she threw the snowball.

Thus, some where questions regarding the location of events are answered by giving the location of the patient, notwithstanding the fact that essential elements of the event are located elsewhere. Experiences are events that befall us under certain circumstances. Where questions regarding them are answered by giving the location of the patient, notwithstanding the fact that essential elements of the event are located elsewhere. The cases are exactly parallel, so if Susie can be an essential constituent of the attack on Johnnie, then the stars can be constituents of the experience of walking on a clear night.

There are two ways in which an event may take place at the Empire State Building. The first is from the outside, as with a lightning strike on its rod. The second is on the inside, as when a meeting occurs on the seventy-first floor. Objective or semi-objective experiences are more like lightning strikes than they are like meetings. They are, in this sense, external events.

\footnotetext{
${ }^{11}$ Compare Judith Thomson's suggestion that 'the place of (x's verbing of $y$ )' might be best "understood as non-extensional" (132).
} 
The fact that experiences are external events solves various puzzles that might otherwise arise from the fact that experiences occur where their subjects are. It solves Valberg's paradox of how objects can be present to experience even though experiences occur where their subjects are. Likewise, it solves the puzzle of how experiences can be present to a subject while depending on the occurrence of events and states that may lie partially outside the subject. The location of the subject only answers one question about the location of the experience. It doesn't exclude the possibility that the experience might have participants beyond the subject.

\subsection{Counter-Arguments Rebutted}

I should criticize arguments for treating experiences as purely internal events, beginning with some offered by Fred Dretske. ${ }^{12}$ First, he argues, they (and thoughts) "have to be in the head (or at least somewhere in the body) if our having them is (sometimes) to explain why we act the way we do" (35). I think this argument is fallacious. In order for an experience to affect an action, perhaps it must affect the agent's brain, but it isn't necessary for it to be inside her head. The behavior of my friends affects my actions and helps explain them, but there's no sense in which their behavior is in my head. I don't mean to deny that I have to have a mutable brain in order to be affected by my friends. My only point is that Dretske's inference from $x$ affects $A$ 's actions to $x$ is in $A$ is fallacious.

Second, he argues,

experiences have to be in us in order to explain why, for instance, I cease to experience a room full of people when I close my eyes. The room full of people does not vanish, but something ceases to exist when I close my eyes. And this something has to be in me or a state of me. Why else would its existence be so utterly dependent on the state of my eyelids? (35-36)

12 Tye (332) and Harman (668) concur without argument. 
In this context, the infinitive 'to experience' just means 'to be aware of through the senses or through introspection. ${ }^{, 13}$ Assuming that the people in the room are very quiet, Dretske would cease to be aware of the people when he closes his eyes because he can't see them any more. As for my topic, experiences as events, we need to be clear about what he's talking about. If it is the experience of seeing a room full of people, it ceases to exist because the grounding event of seeing a room full of people ceases to exist. If it is the experience of being in a room full of people, that doesn't cease to exist when he closes his eyes, not even if everyone is very quiet. There's just a lull in the action. The experience of standing on the edge of the Grand Canyon doesn't cease when the stander closes her eyes. The experience of being chased by the Bolivian army doesn't go away when the fugitive closes his eyes. The experience of owning the largest sheep farm in Arizona doesn't end when the owner closes her eyes. What's so special about the experience of being in a crowded room?

The most that Dretske's eyelid example could show is that experiences partly depend on the person having the experience. That's true, of course, and is a consequence of my account. Nevertheless, it doesn't follow that experiences are entirely in the head.

Nor is there any ontological benefit in restricting the occurrences of experiences to the boundaries of the cranium. The Tigris River and the tennis player's mother, when seen through the cold and unloving eyes of the reductive materialist, are material objects just as much as any portion of brain tissue.

If somebody takes it the wrong way, it's actually somewhat insulting to be told that one's experiences occurred entirely in the head. The résumé inflator may invent his putative experiences, and Walter Mitty's may be mostly imaginary, but my experiences are genuine. I really did those things; that really happened to me. One way can deny the objective

13 This is what Hinton calls the 'b sense' of 'experiencing' (13-21). 
occurrence of an experience is to say that it only occurred in a deluded person's head. Of course, when Dretske says that my experiences only occurred in my head, he doesn't mean it as insult. Nevertheless, the fact that it can be taken that way suggests that there's something fishy about his claim.

\subsection{Times of Experiences}

I'll finish by considering questions of timing. I earlier said that experiences were stretched out over time, and it may clarify matters to be more definite. It seems to me that an experience cannot occur before the grounding event or state has started or after it has halted. Even though fighting in a war may affect a person for the rest of his life, the experience of fighting in a war must end when the fighting does.

At this point, I run the risk of contradicting myself. Earlier, I said that states occur all at once and events are stretched out over time. Now I say that events last no longer than their grounding events or states. Let me clarify that when I write that an experience cannot occur before a state has started or after it has halted, I mean that an experience can't occur outside the period in which the subject is in the relevant state.

A related worry concerns experiences of accomplishments. What are we to say of 'the experience of reaching the summit of Mt. Everest'? ${ }^{14}$ To my ear, to inquire into an experience is to inquire into a stretch of time, and when someone asks about the experience of reaching the summit of Everest, she's looking for a story, the culmination of which is the last few steps. Others might reply that they are interested in how the climber felt at the very instant at which he reached the highest point on Earth.

\footnotetext{
${ }^{14}$ I owe the objection to a referee.
} 
As I said, my present project isn't an analysis of feelings. Nor am I analyzing the sensations that a person might have at a moment or what a person might see. I'm interested stretches of people's life stories. There's good philosophical work to be done in describing momentary states of mind, but that isn't the work that I'm undertaking right now. The experience of feeling lightheaded is part of my subject, but, if my arguments have been any good, the experience of feeling lightheaded should be distinguished from the feeling itself.

Though necessary, the occurrence of the grounding event or state isn't sufficient for the occurrence of the corresponding experience. A case of pancreatic cancer begins when cells first begin to divide uncontrollably. The experience of having cancer begins either when a diagnosis is made or when the first symptoms arise. Suppose Joe has an undiagnosed case of cancer which has not yet manifested any symptoms. If Joe dies in a car wreck, then he never had the experience of having cancer.

The medical distinction between diagnosis and symptom suggests two quite different ways in which an event or state may become the kernel of an experience-one dispositional and comprehending, and the other occurrent and unknowing. For an example of the first kind of experience, the comprehending kind, consider the experience of being director of marketing for IBM. That experience includes everything that the director is aware of that is connected, directly or indirectly, to her professional life. She doesn't need to be actually thinking to herself 'hey, I'm director of marketing' in order for those episodes to be elements of her experience. Her awareness can be a dispositional, cognitive grasp of the grounding state.

Sometimes a person has an experience of a grounding event or state without knowing that the grounding event or state is happening. An ancient Mayan who first suffered symptoms and then died from pancreatic cancer had the experience of having 
pancreatic cancer whether or not he knew that he had pancreatic cancer or, indeed, whether he knew that he had a pancreas. In such cases, the experience of $\phi$ begins not when the person first begins to undergo $\phi$ but when undergoing $\phi$ starts to make a noticeable difference to his life. The experience ends when either grounding event or state ends or it stops making a noticeable difference in the person's life. If the event or state makes only an intermittent difference to his life (as when the symptoms come and go), then the experience is likewise intermittent. By 'making a difference' I mean to compare the subject's life with how it would be if the grounding event were to halt, not to compare it to some subjectively similar experience. Getting into Nozick's Experience Machine makes a difference to one's conscious life relative to the machine's breaking down; being deceived by a Cartesian demon makes a difference to one's conscious life relative to the demon's taking an ichor break.

When we say that experiences occur when they make a noticeable difference in the subject's life, I would like to add that they need be noticed at the time of their occurrence. Against this addition, consider Hinton's colorful tale of counter-revolution: suppose a young man tells you that when he and his friend Peter were conscripts, sent to suppress revolution in a distant former colony, and were taken prisoner, Peter had the experience of being operated on, in a field hospital of the revolutionaries, for the removal of six bullets. Your informant's using the word 'experience' may lead you to assume that they were not able to give Peter a general anaesthetic, but only a local or regional one, or only rice wine, or nothing at all. However, you may be inclined to let the word 'experience' pass even if you are told that Peter did have a general anaesthetic and was completely unconscious throughout the operation-no simultaneous relevant awareness, presumably (9).

I am not, personally, inclined to let this pass. That's partially a matter of linguistic intuition about which people may disagree.

As a matter of metaphysics, however, it doesn't really matter what we call it, since such an experience would just be an ordinary event labeled an 'experience' because of later consequences. And, indeed, this is how Hinton looks at the matter (5-6). If, on the other 
hand, we are interested in experiences as a metaphysically distinctive sort of event, one partially constructed out of subjective awareness, we should restrict our attention to instances in which Moore's condition holds and in which the experience includes the awareness of something.

To sum up, experiences are complex events that befall their subjects. An experience of a grounding event or state occurs when that event or state makes a difference to its possessor's conscious life, where this difference is either a matter of really knowing what's happening or just a matter of being affected. The experience occurs where the person having the experience is, though not necessarily in the person's head. An experience depends on its subject, its grounding event or state, and everything that the subject is aware of during that time that's relevant to the telling of the story of how it was to participate in that event or be put in that state. The participants of an experience include the substances among these and the substances upon which the rest depend.

\section{Bibliography}

Alston, W. "Perception and Representation." Philosophy and Phenomenological Research 70 2005: 253-89.

Anscombe, G. E. M. "Under a Description"” in Metaphysics and the Philosophy of Mind, Collected Philosophical Papers, vol.2. Minneapolis: University of Minnesota Press, 1981.

Aristotle, Physics, R. P. Hardie and R. K. Gaye trans., in The Complete Works of Aristotle, vol. 1, J. Barnes, ed. Oxford: Oxford University Press, 1984.

Byrne, A. "Experience and Content", The Philosophical Quarterly 59 2009: 429-51.

Caplan, B. "Creatures of Fiction, Myth, and Imagination.” American Philosophical Quarterly 41 2004: 331-37. 
Dewey, J. Experience and Nature. $2^{\text {nd }}$ ed. LaSalle, Illinois: Open Court 1929.

-----. Art as Experience. New York: Capricorn Books, 1958.

Dretske, F. Naturalizing the Mind. Cambridge, Mass.: The MIT Press, 1995.

Fine, K. "In Defense of Three-Dimensionalism." The Journal of Philosopby 103 2006: 699-714.

Graham, D. "States and Performances: Aristotle's Test." The Philosophical Quarterly 30 1980: 117-30.

Hacker, P.M.S. "Events and Objects in Space and Time.” Mind 91 1982: 1-19.

Harman, G. “The Intrinsic Quality of Experience.” Philosophical Perspectives 4 1990: 31-52.

Hawthorne, J. “Three-Dimensionalism vs. Four-Dimensionalism.” In Contemporary Debates in Metaphysics, edited by T. Sider, J. Hawthorne, and D.W. Zimmerman. Malden, Mass.: Blackwell Publishing, 2008.

Hinton, J.M. Experiences. Oxford: Clarendon Press, 1973.

Jacovides, M. “Do Experiences Represent?” Inquiry 53 2010: 87-103.

Johnston, M. “The Obscure Object of Hallucination.” Philosophical Studies 120 2004: 113-83.

Kim, J. "Events as Property Exemplifications." In Action Theory, edited by M. Brand and D. Walton. Dordrecht: D. Reidel Publishing, 1976.

Lombard, L.B. Events: A Metaphysical Study. London: Routledge \& Kegan Paul, 1986.

Moore, G.E. “The Refutation of Idealism.” Mind 12 1903: 433-53.

Nozick, R. Anarchy, State, and Utopia. New York: Basic Books, 1974.

O'Shaughnessy, B. Consciousness and the World. Oxford: Clarendon Press, 2000.

Peterson, P. “Complex Events.” Pacific Philosophical Quarterly 70 1989: 19-41.

Ryle, G. Dilemmas. Cambridge: Cambridge University Press, 1954.

Sartwell, C. "Radical Externalism Concerning Experience." Philosophical Studies 78 1995: 5570. 
Schnieder, B. and T. von Solodkoff "In Defence of Fictional Realism.” Philosophical Quarterly 59 2009: 138-49.

Sider, T. "Four-Dimensionalism.” The Philosophical Review 106: 197-231.

Siewert, C. P. The Significance of Consciousness. Princeton: Princeton University Press, 1998.

Simons, P. Parts: A Study in Ontology. Oxford: Clarendon Press, 1987.

Smart, J. J. C. "Sensations and Brain Processes." The Philosophical Review 68 1959: 141-56.

Smith, B. “Acta Cum Fundamentis in Re.” dialectica 38 1984: 157-178.

Thomasson, A. Fiction and Metaphysics. Cambridge: Cambridge University Press, 1999.

Thomson, J. J. “The Time of a Killing.” The Journal of Philosophy 68 1971: 115-32.

Travis, C. “The Silence of the Senses.” Mind 113 2004: 57-94.

Tye, M. "A Representational Theory of Pains and Their Phenomenal Character." In The Nature of Consciousness: Philosophical Debates, edited by N. Block, O. Flanagan, and G. Güzeldere. Cambridge, Mass.: The MIT Press, 1997.

Valberg, J. J. The Puzzle of Experience. Oxford: Clarendon Press, 1992.

Van Inwagen, P. “Creatures of Fiction.” American Philosophical Quarterly 14: 299-308.

Vendler, Z. Linguistics in Philosophy. Ithaca, New York: Cornell University Press, 1967. 